\title{
Ethnicity, Identity and Group Vitality: A study of Burushos of Srinagar
}

\author{
Musavir Ahmed ${ }^{1}$ \\ University of Kashmir, Srinagar, India
}

\begin{abstract}
This study reports the findings of a survey undertaken to comprehend the factors that have enabled a group of around 350 Burushos to maintain their ethnic identity including their language after 125 years of their immigration to Kashmir in Jammu and Kashmir State of India. The group has been able to resist the assimilatory forces and has maintained itself as a distinct entity vis-avis the dominant Kashmiri host society. The study has drawn upon the empirical tool of ethnolinguistic vitality as a reflection of the group's sustainability as a collective entity in terms of their ethnic as well as linguistic identity. The study also reveals the attitude of native Kashmiris towards the group as perceived by group members. This perceived attitude of the group members has been explained in terms of its bearing on the vitality and identity of the group. The study is based on 50 semi-structured questionnaires and four unstructured interviews. The questionnaire has been partly developed on the basis of six factors identified by UNESCO (2003) in the evaluation of ethnolinguistic vitality. The paper concludes that an ethnically small immigrant group can survive the assimilatory forces and maintain their ethnic identity even if the ethnolinguistic vitality of the group is quite low on most of the measurable factors.
\end{abstract}

Keywords: Identity, Ethnolinguistic Vitality, Burushaski, Perceived Attitude and Kashmir

\section{Introduction}

Maintenance or retention of ethnic identity by small immigrant groups in the context of interethnic contact has been less explored than the processes that lead to their adaptation in the receiving society.Researchers over the years have focussed on the adaptive strategies of immigrants in their new places of settlement. In general, this adaptation has been shown to be an outcomeof "an interaction between the attitudes and characteristics of the immigrants and the response of the receiving society" (Phinney et al, 2001, 494). However individual contexts of actual interaction between the immigrants and the receiving society can profoundly impact the outcome of any such interaction. The term acculturation has been widely employed to capture the outcome of inter-ethnic interaction. Acculturation has been defined as "those phenomena which result when groups of individuals having different cultures come into continuous first-hand contact, with subsequent changes in the original culture patterns of either or both groups"' (Redfield, Linton, \& Herskovits, 1936, quoted in Sam and Berry, 2010). In case of a small ethnic group immigrating into a larger receiving society, it's essentially the former that acculturates. Terms like assimilation and integration have also been used with more or less the same meaning. Following Berry (1990, 1997), four acculturation strategies have been identified; integration, assimilation, separation and marginalization, based on whether a group deems it beneficial or otherwise to maintain its own cultural heritage as well as to develop relationship with the receiving society. Integration takes place when a group shows positive response to its own cultural heritage as well as develops good relationship with the receiving society. If the group is neither positive towards its own culture and nor develops positive relationship with the receiving society it has been labelled as marginalization. Assimilation takes place when a group views its own culture negatively and adopts the culture of the receiving society and separation means the group rejects the culture of the receiving society while believing only its own cultural legacy (Phinney et al, 2001).

Apart from these theoretical constructs, it's the always the public policy in the receiving society and the response of the natives that determines fate of immigrant ethnic identity. Some governments promote diversity and therefore respect the cultural heritage of the immigrants, offering these groups ways and means for its preservation. In contrast many countries encourage assimilation for promoting a sense of community and social solidarity and also because it involves public funding (Portes\& Rivas, 2013, p. 224).

\footnotetext{
${ }^{1}$ Correspondence author’s email: ahmed.musavir@gmail.com
} 
What constitutes ethnic identity and what is it that is being preserved in separation or lost in case of total assimilation has been a subject of considerable debate and different theoretical constructs have been proposed towards capturing the contents of ethnic identity.

Jones (1997), has defined ethnicgroup as "any group of people who set themselves apart and/or are set apart by others with whom they interact or co-exist on the basis of their perceptions of cultural differentiation and/or common descent" (1997: xiii). Jones' understanding of ethnic group is visibly comparative and psychological in nature. The a priori existence of other such groups, with which an ethnic group stands in comparison, also lies at the core of her definition of ethnic identity defined as "that aspect of a person's self-conceptualization which results from identification with a broader group in opposition to others on the basis of perceived cultural differentiation and/or common descent". For her, ethnicity is the manifestationof the "social and psychological phenomena associated with a culturally constructed group identity". Again taking a comparative view, she notes that in the realization of ethnicity, an interaction of the social and cultural processestakes place "in the identification of, and interaction between, ethnic groups" (1997: xiii).

In his understanding of ethnic identity, Isajiw (1993: 8) has emphasized its internal and external aspects. External aspects refer to the observable content of ethnic identity and the internal reflect the psychological ones. In the external, he places, "speaking an ethnic language, practicing ethnic traditions", "participation in ethnic personal networks, such as family and friendships", "ethnic institutional organizations such as churches, schools, enterprises, media", "ethnicvoluntary associations, such as clubs" and "functions sponsored by ethnic organizations such as picnics". Internal aspects refer to the subjective entities like "images, ideas, attitudes, and feelings" (ibid: 8). The sociopsychological perspective of ethnic identity proposed above is again to be perceived in a comparative perspective, for according to Isajiw, ethnic identity refers to the "manner in which persons, on account of their ethnic origin, locate themselves psychologically in relation to one or more social systems, and in which they perceive others as locating them in relation to other systems".

What emerges from the above two perspectives is that ethnic identity, whatever the social, cultural and psychological attributes associated with it, has to be understood in intergroup perspective. The sense of us versus them is inherent to the understanding of ethnic identity. The boundaries between the ethnic groups are as much psychological as cultural and social. The observable content of an ethnic group together with the subjective group feeling places a specific group in contrast with all other ethnic groups whose own contents and feelings give them a distinct identity distinct from the particular group.

However in the understanding of ethnic identity more emphasis has been laid on the subjective content of ethnic identity carried by a group. For Phinney et al (2001), ethnic identity embraces "selfidentification, feeling of belongingness and commitment to a group, a sense of shared values, and attitudes towards one's ethnic group". The strength of such feelings has been conceived in terms of what has been called as ethnic thickness or thinness. A strong sense of group commitment and solidarity is reflective of ethnic thickness, while as a loose connection denoted ethnic thinness (Cornell and Hartmann 2007, 85-89).

The static versus dynamic approaches to ethnic identity have been the two leading theoretical approaches in the debate on ethnic identity during the closing decades of last century. The static perspective known as primordial approach emphasizes the bonds that exist between individuals in a group "from the givens of birth - 'blood', language, religion, territory and culture" (Jones, 1997, 65). Since such bonds are involuntary and as such "possess a coerciveness which transcends the alliances and relationships engendered by particular situational interests and social circumstances" (ibid). These primordial attachments resist any force aimed at nationalizing or assimilating in the context of migration, as these provide a "natural and fundamental form of identity than other forms of social identity" (ibid, 66).

In contrast to the primordial, the instrumentalist perspective places ethnic identity in the changing social situations (Cornell and Hartmann 2007, 62).Instrumentalist approach has been more concerned "with the role of ethnicity in the mediation of social relations and the negotiation of access to resources, primarily economic and political resources" (Jones, 1997, 72). Ethnic identities are continuously renegotiated on the basis of the specific situations and circumstances faced by the individuals. However the instrumentalist, also called as constructionist approach has often been criticized for foregrounding only the economic and political interests of groups and relegating the cultural contents of ethnicity to backburner. "Ethnicity is constructed in certain situations for instrumental reasons, political, economic or other" (Westin, 2010, 13).

Empirical studies carried on immigrants have suggested the possibility of multiple identities contradicting the unidirectional model of identity. As per the unidirectional model there is always a negative correlation between the immigrant identity and the national identity, implying that any loss in the immigrant identity necessarily involves assimilation in the receiving society. However it has been 
shown that there isn't actually any correlation between the measures of two identities and "that the linear measures of two types of group identities are usually statistically independent" (Phinney et al 2001, 497). This bi-directional model lies at the centre of acculturation theory originally forwarded by Berry $(1990,1997)$ that identifies the four theoretically possible stages of adaptation; integration, assimilation, separation and marginalization. The view has been upheld by Zimmerman (2007) in his study on the immigrants in Germany. According to him, "ethnic identity is the balance betweencommitment to, affinity to, or self-identification with the culture, norms, and society of origin and commitment to or self-identification with the host culture and society" (4). He completely rejects the unidirectional model by maintaining that "Individuals may exhibit strong association with and commitment to either or both the culture of ancestry and host culture" (ibid).

Recent works of Pennycook (2003) and Maher (2005) are quite significant in the context of instrumentalist or socially constructed fluid ethnic identities. Commenting on the relationship between language and identity in the context of global use of English, Pennycook (2003) raises serious doubts about the notion of predetermined linguistic identities. People use languages to perform and create their identities rather than using them because of their identities. To explain this, Pennycook resorts to the use of the term performativity. He defines it "as the way in which we perform acts of identity as an ongoing series of social andcultural performances rather than as the expression of a prior identity" (2003: 528). Accordingly, an a priori linguistic identity does not exist; since it's the users of a language who recreate their identities by the performative acts of the language. In the process of repeating their earlier performative acts, users of a language bring in changes and adjustments in these acts for their performance in new discourses thereby creating new identities for them (Pennycook 2007b). Simultaneously the earlier norms of language give rise to new norms, new rules and new meanings for the language. The performative acts are thus processes of "disinventing" and "reinventing" language for the creation of new identities for its speakers (Pennycook 2004: 6-7).

The term "metroethnicity" proposed in Maher (2005) to refer to the non-static and nonpermanent, perpetually changing conception of ethnicity, again emphasises the fluid model of identity. He calls metroethnicity "a reconstruction of ethnicity: a hybridized 'street' ethnicity deployed by a cross-section of people with ethnic or mainstream backgrounds who are oriented towards cultural hybridity, cultural/ethnic tolerance and a multicultural lifestyle in friendship, music, the arts, eating and dress" (Maher 2005: 83). The contexts for such ethnicities are provided by the urbanized cosmopolitan settings as has been maintained by Ramanathan and Pennycook (2008); "metroethnicty is an emergent possibility only for those living within certain conditions of globalization, in contexts where there is easy access to forms of multicultural life ... and where class, cultural, racial, religious or ethnic conflict are not a daily threat" (p. 24). Metroethnicities need not to have a physical space for expression, rather these works move on a conceptual plane and offer an "alternative means of conceptualizing community and belonging" (Maher 2010: 579). As such, metroethnicities are need based rather a simple mixing of two or more identities as these "do not make impossible demands but rather fulfil utilitarian needs" (2010: 581).

In the context of inter-group perspective on ethnicity, an important research tool was developed by Giles et al. (1977) and Harwood et al. (1994) by the name of "ethnolinguistic vitality". In the understanding of the dynamics of ethnicity, the concept holds much significance, given the number of studies, both theoretical and empirical, it has inspired. Ethnolinguistic vitality has been defined as "that which makes a group likely to behave as a distinctive and collective entity within the intergroup setting" (Giles et al. 1977: 308). The vitality of an ethnic group can be low, high or medium depending on three types of variables. The variables are:

a. Status factors: economic, political and linguistic prestige.

b. Demographic factors: absolute number, birth rate and geographical concentration.

c. Institutional support: recognition of the group and its language in media, education and government.

Ethnic groups that are strong in terms of the three variables have a high vitality thus ensuring the survival and existence as a collective entity (Harwood et al. 1994: 168). In intergroup settings, status may rather be taken as relative status. The relative status of an ethnic group within the context of intergroup setting increases the vitality in as far "high status group positions can contribute to a more positive social identity for group members" and increases collective will of the group to sustain themselves as a distinct linguistic community (Harwood et al. 1994: 170).

Demographic factors, besides the number of individuals representing the group, reflect the concentration of group members in and outside the traditional homeland as well the patterns of immigration and emigration. Support of thegovernmental, social and media institutions in terms of the representation, the group and its language has received "serve to enhance their vitality as a distinctive collective entity" in comparison to those groups who lack this kind of support (Harwood et al. 1994: 
168). Institutional support is further enhanced by the quality of leadership produced by the community who can represent it at various forums (1994: 170). However, significance of language and language use is much more in any study involving ethnicity. Citing several studies, the point has been emphasizedby Sachdev (1995). According to him "language use and identity appear to be related reciprocally: language use influences the formation of group identity and group identity influences patterns of language attitudes and usage" (1995: 42).

Phinney, Romero, Nava and Huang (2001) have shown a positive relation between language and identity in a study involving adolescents of 3 immigrant groups in US: “. . . ethnic language proficiency had a positive impact on ethnicidentity among adolescents across the 3 immigrant groups" (2001: 148).

UNESCO (2003) has also identified six major evaluative factors for determining language vitality. The six factors include: (1) intergenerational language transmission; (2) absolute number of speakers; (3) proportion of speakers within the total population; (4) trends in existing language domains; (5) responses to new domains and media; and (6) materials for language education and literacy. Each of the six factors is to be assessed along a six point scale denotingthe degree of endangerment with grade 5 signifying "no threat" and grade 0 as "extinct". Intergenerational language transmission refers to the transmission of language to younger generations of the group; the greater the number of members of younger generations acquiring the language as their first language, the lesser is the chance of it becoming extinct. Trends in existing language domains reflect the use of language in the individual and the collective life of the group. If the language is actively used in all the domains of interaction by the group members, then its vitality is obviously high. These include official domains of educational institutions and government offices. New domains of language use include "Schools, new work environments, new media, including broadcast media and the Internet" (UNESCO 2003: 11) and whether a language is given representation in these domains significantly affects its vitality. Materials for language education and literacy refer to the written form and orthography of the language. If the language has a well developed orthography then its vitality is high and its chances of extinction are least. Grade 5 on this factor is accorded to those languages which have a "literacy tradition with grammars, dictionaries, texts, literature, and everyday media" and also where "Writing in the language is used in administrationand education" (UNESCO 2003: 12). This indicates that oral tradition in a languagedoes not contribute so much towards its vitality as does a well establishedorthography and a written tradition.

\section{Burushos of Srinagar}

The Burushos (the speakers of Burushaski ${ }^{2}$ language) of Srinagar comprises of a group of around 340 individuals who live in a close-knit community in a locality called as Botraj Mohalla ${ }^{3}$ towards the south-east of Hariparbat fort in Makhdum Saheb area of Srinagar. The community is the progeny of two princes, one of Hunza ${ }^{4}$ and another of Nagar ${ }^{5}$ who along with their families and some attendants migrated to Kashmir towards the closing decades of nineteenth century. The then local ruler received them with generosity and granted them several hundred kanals of land as well as state pension was fixed for them. At present the forty odd households occupy a total of around 30 kanals of land. The community, whose elders migrated to Srinagar from Hunza and Nagar in 1888, have to a large extent maintained their identity as a distinct group as well preserved their language.

Even though the use of Burushaski is restricted to home and immediate neighbourhood, yet all the members of the group, including the children, acquire it as their first language. Besides Burushaski, all the members of the group can speak Urdu and Balti. The adult members can communicate in Kashmiri with quite ease.

\footnotetext{
${ }^{2}$ Burushaski is a language isolate primarily spoken in north Gilgit district areas, Hunza, Nagar and Yasin areas in the Gilgit-Baltistan province of Pakistan. (http://www.ethnologue.com/language/bsk).

${ }^{3}$ Mohalla is the Urdu term for locality or neighbourhood.

${ }^{4}$ A former princely State, now part of Gilgit-Baltistan in Pakistan.

${ }^{5}$ A former princely State, now part of Gilgit-Baltistan in Pakistan.
} 


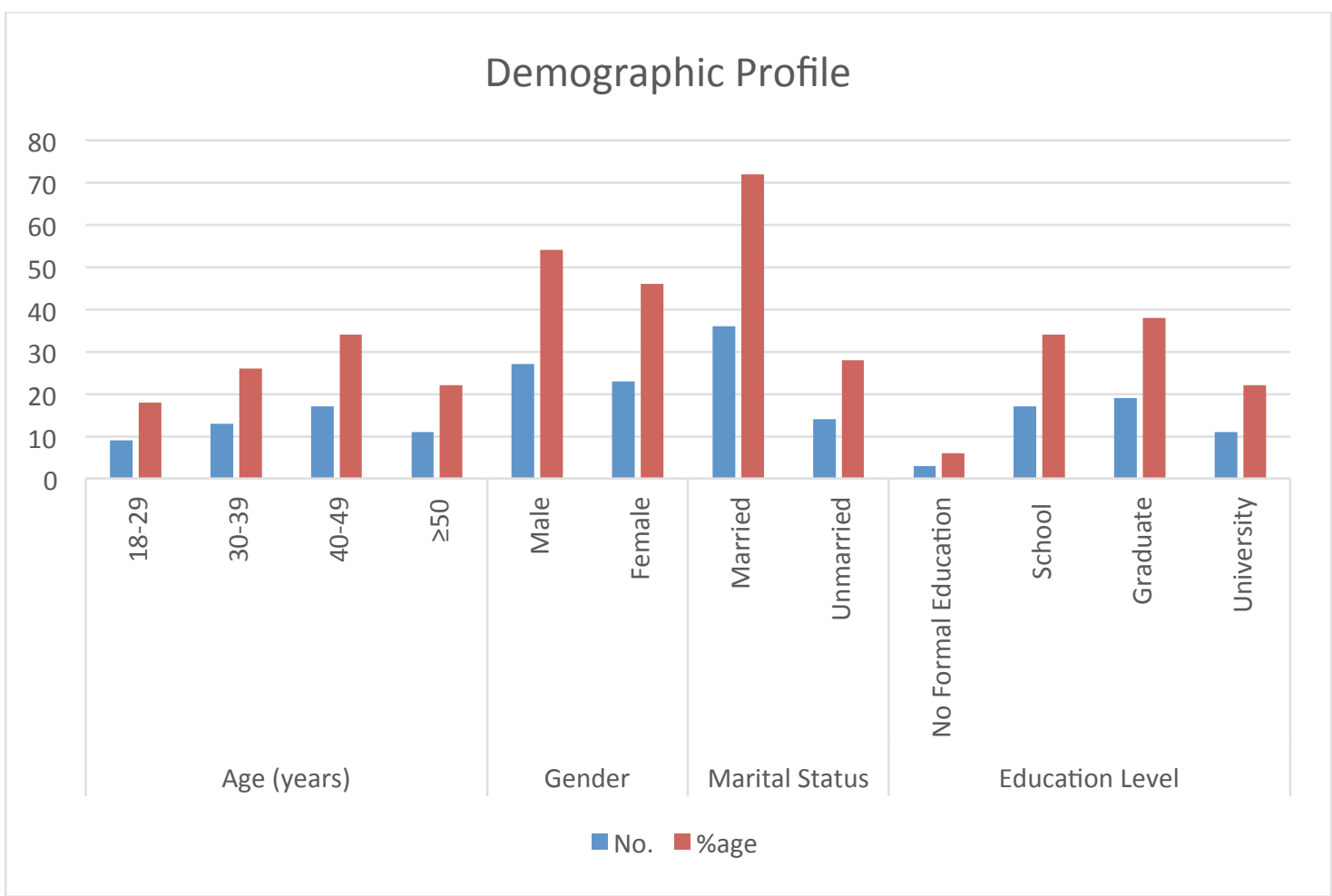

Results

Figure 1. Demographic Profile of Participants

\section{Language use patterns}

All the participants reported the use of Burushaski with other members of their households. Their domestic language is Burushaski; no other language is used in home domain even though the adult group members are well acquainted with Urdu and Kashmiri. The language of socialization of younger members of the group takes place in Burushaski which creates a sense of identity among them. This exclusive use of Burushaski in homes contributes significantly towards the maintenance of their ethnicity as well as increases group vitality. Since the immediate locality called as Botraj Mohalla with around fifty households is entirely owned by the Burushos, the members have the freedom to use their own language in the immediate neighbourhood. Leisurely talks between womenfolk, informal chats among neighbours, community related discussions, children's play, adolescent meetings etc are carried in Burushaski. Given the facts that the 350 members of the group are actually members of two extended families with known heads, quitesimilar in structure to that of two clans and the inbreeding that has taken place during the past century, every member is somehow a kin of every other member. This is reflected in the strong emotional bonds the Burshos share with each other and has positive consequences for group identity.

During certain community events the group members use Balti ${ }^{6}$ language besides Burushaski. Balti has a special place in the religious affairs of the group. Burushos of Srinagar follow the Shia sect of Islam and for the followers of this sect the Muharram celebrations are an important component of faith. Throughout the Shia world during the Islamic calendar month of Muharram tributes are paid to Hussian, the grandson of Prophet Muhammad in the form of poetic eulogies. These poetic eulogies are called as Marsia. Since the Burushos of Srinagar have no knowledge of written form of Burushaski, the members have exclusively relied on the eulogies written in Balti. According to the eldest member of the group, Balti language has a rich tradition of the eulogies written in the memory of Hussain and during Muharram, Burushos recite these with quite a zeal.

Outside the Botraj Mohalla, the entire scenario of language use pattern change. For elder members who are in government jobs or who have retired from services, Kashmiri is the preferred language in the market place and during travel in the public transport. For middle aged Burushos both Kashmiri and Urdu serve the purpose in this public domain. While for students who are still in schools, colleges or universities, Urdu is the preferred option. The reason for this pattern is that the elderly members have a fairly good command on Kashmiri in comparison to the younger members. Similar

${ }^{6}$ Balti is spoken in northeast Pakistan, Northern Areas, Hunza-Nagar district; Baldistan region, Skardu, Rondu, Shigar, Khapalu, Kharmang and Gultari valleys(http://www.ethnologue.com/language/bft.). It is also spoken in Kargil district of J\&K in India. 
pattern is found in other domains like working places and educational institutions. Elder people use mostly Kashmiri and sometimes Urdu in their places of work while as students use only Urdu in their educational institutions. Urdu being the lingua franca of the state as well as the official language, Urdu is otherwise used in several domains of society by natives of other languages including Kashmiri like schools and colleges and government offices where people of different regions of the state have to interact on daily basis.

\section{Ethnolinguistic Vitality}

Burushos of Srinagar score very low on the three variables proposed by Giles et al. (1977) for measuring ethnolinguistic vitality and the six evaluative factors identified by UNESCO (2003) to ascertain language vitality. With a population of approximately 350 persons in a host population of more than seven million people, demographically the group vitality of Burushos of Srinagar is significantly low. These numbers doesn't come close to even quarter of a percent of the total population of Kashmir division. As already stated in section ... language use is restricted to home and immediate neighbourhood and there isn't any scope of any additional domain of their language use in future. The group has no knowledge of written form of their language nor have there been any efforts on the part of the group to gain such knowledge. Since the parent group of Burushos in Hunza and Nagar in the Gilgit-Baltistan have been out of bounds for the Burushos of Srinagar, the group has never received any motivation to develop written form of their language. This further decreases the ethnolinguistic vitality of the group. There is practically no institutional support for the group as far as the recognition of the group or its language in media, education or government is concerned. However the group has a few positives with regard to its vitality. The intergenerational transmission of Burushaski language among the Burushos is the single most important factor that has contributed towards the group vitality. The group members are conscious about the importance of transmission of their language to the younger members. Considering their language the most significant of the elements of their ethnic identity, the elders ensure that the infants acquire Burushaski as their first language. All the participants want their children to acquire Kashmiri, Urdu and English, besides Burushaski, however with regard to the first language, the participants report that in no case it should be any language other than Burushaski.

\section{Perceived Attitude}

All the participants in the study feel proud in being called as Botraj by the dominant Kashmiri community. The term "Botraj" is a compound word comprising of "boti", the Kashmiri appellative for people of Mongoloid origin and "raj" derived from "raji" means king. So the compound roughly translates as Mongoloid Kings or Mongoloid chieftains. Being the descendants of two princes, the Burushos consider themselves as above the ordinary Kashmiris. According to the elders, inbreeding is the norm and preferred form of marriage and if at all they marry in Kashmiri community, the latter should be from upper castes preferably the Sayyids ${ }^{7}$. According to the Burushos, the Kashmiris treat them with respect and acknowledge their superior genealogy. This respect is reflected in their interaction with the Kashmiris who live in the vicinity of their locality. Burushos believe that their ancestors were generous towards the Kashmiris and would regularly donate to poor who would come to them for help. The community elders are requested by Kashmiris in the vicinity to arbitrate in their family and other disputes from time to time.

This feeling of self-respect coupled with their perceived attitude of Kashmiris towards them raises their ethnolinguistic vitality. This is unlike many other small ethnolinguistic communities in Kashmir like Gujjars or Dards who feel discriminated by the dominant Kashmiris. Ahmed (2013) has reported that the Dards of Gurez feel that they are discriminated by Kashmiris because of their social backwardness, their language and sometimes because of the life style of their older generations (12-13). There is no feeling of being discriminated or dominated by Kashmiris among the participants of the study.

\footnotetext{
${ }^{7}$ Sayyids lie at the top of the caste hierarchy in Kashmir. These are considered to be the descendants of the people who migrated from various parts of Central Asia to preach Islam in Kashmir. The migration of these Islamic preachers to Kashmir started in $14^{\text {th }}$ century and continued for several centuries.
} 


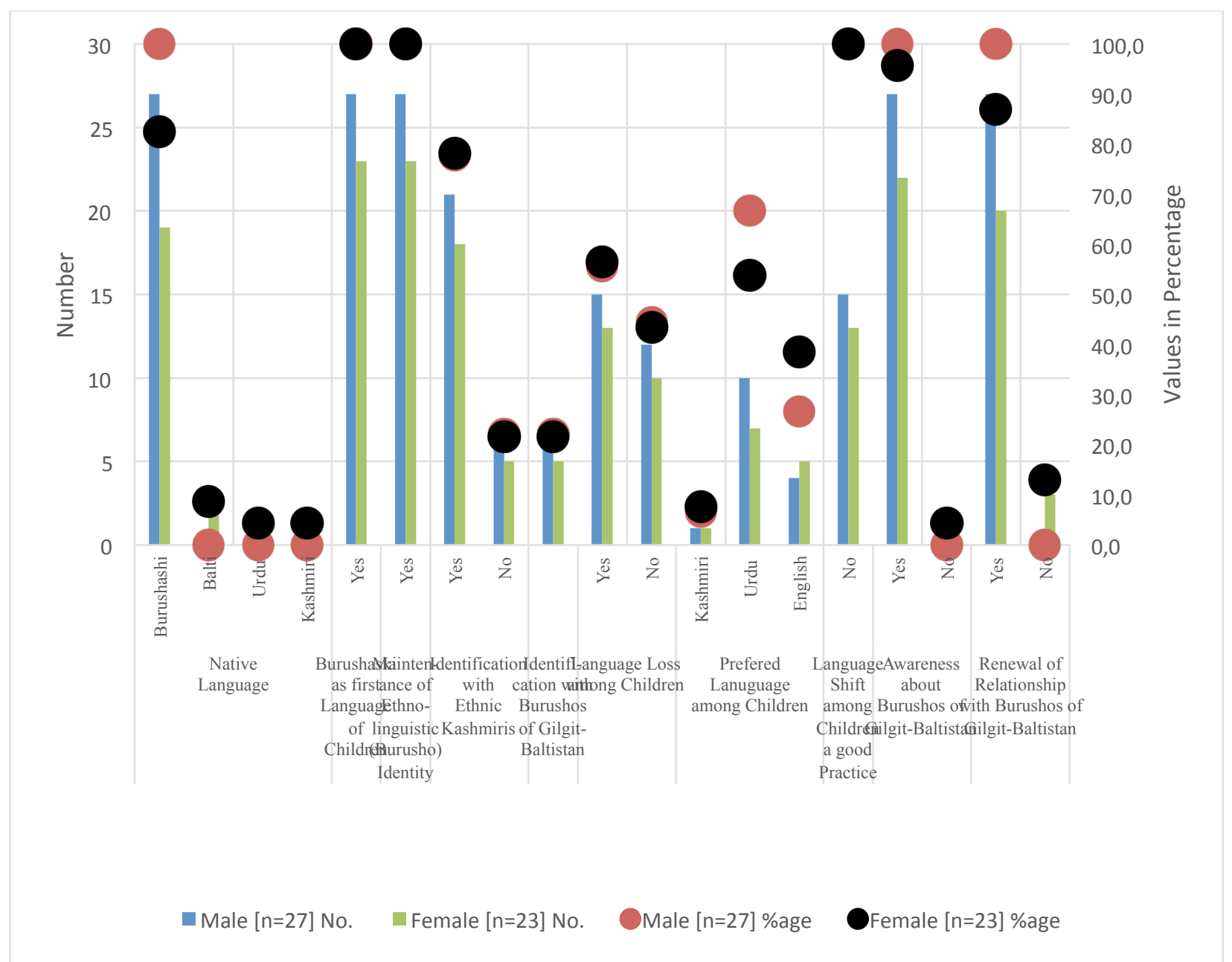

Figure 2.Language-use patterns, Perceived Attitude, Language Shift and Relationship with Host Society among Burusho Immigrants

Relationship with the Burushos of Hunza and Nagar

All the participants reported that their ancestral land is Hanza/Nagar in Pakistani province of Gilgit-Baltistan, but only some of them want to be part of the greater Burusho community. The community has no contact with their Burushos of Gilgit-Baltistan since 1947, when partition of India and Pakistan necessitated the division of the erstwhile princely state of Kashmir. No participant was ready to move to Hunza/Nagar if provided a chance. Interestedly all the participants reported that they want to be associated with Kashmiris. The elders desired that they want to be called as Kashmiri Bots meaning Kashmiri-Mongoloids. They have a strong affection for Kashmir and believe they are as much Bots as Kashmiris. Among the reasons for not migrating to Hunza/Nagar - their ancestral land, if given a chance, the participants reported the following:

a. that they are quite content in Kashmir

b. that they are well adapted to Kashmiri environment.

c. that they have love and affection for Kashmir and Kashmiris

d. that they feel privileged and satisfied in Kashmir

Significantly Burushos have been designated as 'tribal' by the state government like many other such groups like Gujjars, Dards, these groups have been granted reservation in government jobs and educational institutions and most members of the community are in government jobs.

Ethnic Identity

Among the external constituents of ethnic identity, Burushso have so far managed to preserve their language in family and neighbourhood domains. Language is the most significant component of their ethnicity, which they have been exploiting positively to create a sense of group feeling among the members. Particularly among the younger members of the group, language was found to be the notable distinction that sets the group apart from the Kashmiris. Muharram celebrations (see section) along with the eulogies in Balti language that form essential part of these celebrations constitutes the visible ethnic traditions that the group have been maintaining over the years. These celebrations set the 
Burushos apart even from Kashmiri Shias who also celebrate Muharram with eulogies written and spoken in Kashmiri and Urdu. The group has also been able to preserve a few cooking recipes and the Burusho families prepare these non-Kashmiri dishes occasionally. Apart from these, there is hardly anything observable that differentiates the Burushos from native Kashmiris. Marriage ceremonies, mourning rituals, food patterns, dresses of Burushos are same as that of the Kashmiris. However with regard to the internal aspects of ethnic identity, the members strongly hold the feeling of a group distinct from Kashmiris. The sense of being different from Kashmiris is strong among the group members. Looking closer at these feelings the Burushos have for their group, it emerges that the feelings are more based on the fact that the former are descendants of princes or members of the ruling class as against the common Kashmiris who are the ruled lot and less on them being Burushos. The members of the group are quite content with their present status of being called as Botraj (Kashmiri Mongoloids).Kashmiris in general call people of Mogoloid origin as Bots, regardless of their place of origin. A Chinese or Japanese or a citizen of the Ladakh division of their own state is labelled as Bot by Kashmiris. And the Burushos are the only Mongoloid group in J\&K state who receive the appellation 'Raj' (king or chief) along with the term Bot (Mongoloid). Since Kashmiris living in the periphery of the Burusho Community call them as Botraj, the group members reported that they feel proud in being called so.

\section{Discussion}

The Burushos of Srinagar have successfully maintained their identity as an ethnic group over the past more than a century in a host society where all the social and public domains are dominated by ethnic Kashmiris. During this period there has been no report of any discord or dispute between this numerically very small group and the dominant host community of Kashmiris. In a community where members of other ethnic groups like Dards of Gurez try to hide their ethnic identity in social domains dominated by ethnic Kashmiris (Ahmed 2014), the Burushos of Srinagar feel proud in expressing their ethnicities, at least in their immediate neighbourhood.The results point to the single most factor of "self- identification" by members with the immediate ancestors or forerunners of the group who have been princes or chieftains. This feeling of belonging to the extended family of princes or chieftains has inculcated a sense of pride among the members. This feeling is reinforced on a daily basis by the attitude of ethnic Kashmiris in the immediate neighbourhood towards the members of the group who actually treat them as the progeny of the princes or chieftains and hence the epithet of Botraj. This feeling is, as reported by the participants of the study, stronger than the feeling of being Burusho, even though empirically, it was difficult to measure the two feelings separately.

Among the external aspects of their ethnic identity, the Burushsos have only been able to preserve their language in their home and neighbourhood domains and the ten-day long Muharram celebrations with its proceedings carried in Balti language; the group has adopted the cultural ways and traits of ethnic Kashmiris. Even though the members marry within the group, marriage ceremonies are carried strictly according the ethnic Kashmiri traditions. This is also reflected in the language use patterns of the group. The elder members of the group talk in Kashmiri and/or Urdu with natives in the different social contexts but exclusively in Burushso with the group members.Even the elder members of the group have reported that they are as much Kashmris as they are Bots (Mongoloids). This reflects adaptation to the native socio-cultural and geographical environment by the Burushos. The group has been able to retain only those elements of external aspects of their identity as would have been possible for any such group. In the broader Kashmiri society that is outside their immediate neighbourhood, the members of the group confirm to the norms of the ethnic Kashmiris, be it the language or dress or food or any other thing. It is because ethnic Kashmiris in the immediate neighbourhood may treat a Burusho with respect given their knowledge of the presence of the group, but an ethnic Kashmiri from another part of the valley would treat these like other Bots and may not display such respect. It's for this reason of losing the respect from ethnic Kashmiris in the immediate neighbourhood that the Burushos have not moved to live outside the locality of their ancestors. Outside this locality the group members may lose their identity and the chances of these becoming ordinary Bots, thus losing the character of Botraj, are much greater. The younger members of the group are socialized in the immediate locality where Burusho peer groups are available and if any of the family moves out this locality, the ethnic identity ofsuch members will beseverely impacted.

As already discussed in section.... the ethnolinguistic vitality on most of the measurable counts is severely low; only the intergenerational transmission of their language and its use in home and neighbourhood domains brings in some strength to it. Here again the feeling of being the progeny of princes or chieftains comes into play. The members of the group consider Burusho as the language of their forerunners who were princes or chieftains and thus superior to the native Kashmiri language, rather than it being the significant marker of their ethnic identity. From the observation, it may be 
presumed that had the forerunners of the group not been Princes or Chieftains, the members may not have such a sense of belongings towards the group. The assumption can be substantiated by the observations on the marriage patterns of the group. Since the members consider themselves as the progeny of the princes, as such they can't marry only among themselves. In case there is a need to marry outside the group, it could only be the Sayyids, the highest ranking caste among Kashmiris. Even though the feeling of being a Burusho and that of being the progeny of princes or chieftains among the group members can't be separated and observed separately, but the fact of matter is the latter predominates the former.

As a conclusion the paper underscores the significance of the subjective feelings of superiority among a small ethnic group vis a vis a dominant host society in determining its vitality; the strength of such feeling can have severe impact on the ethnolinguistic vitality. Strong subjective feelings among the members can raise the ethnic vitality of a group and thereby help in the maintenance of its identity as an ethnic group, even when it scores low on most of the measurable counts of vitality. The conclusion is in conformity to the observation of Phinney et. al (2001) that stronger feelings of "belongingness" and "self-identification" increases the ethnic thickness of a group.

\section{References}

Ahmed, M. (2014). Language use patterns and ethnolinguisticvitality of the Shina speaking Gureziimmigrants. International Journal of Sociology of Language, 230, 1 - 17.

Berry, J.W. (1997). Immigration, acculturation and adaptation. Applied Psychology, 46, 5-68.

Westin, C., Bastos, J., \&Dahinden, J. (Eds.). 2010. Identity processes and dynamics in multiethnic Europe. Amsterdam, Netherlands: Amsterdam University Press.

Buzan, B., Wæver, O.,\&de Wilde, J. (1998). Security: A new framework for analysis. Boulder, CO: Lynne Rienner.

Commission on Human Security (CHS). (2003). Outline of the report of commission on human security. Retrieved fromhttp://www.unocha.org/humansecurity/chs/finalreport/Outlines/outline.pdf

Cornell, S.,\&Hartmann, D. (2007). Ethnicity and race: Making identities in a changing world. (2nd ed). Thousand Oaks, CA: Pine Forge.

Sam, D. L., \& Berry, J. W. (2010). Acculturation when individuals and groups of different cultural backgrounds meet. Perspectives on Psychological Science,5(4), 472-481.

Davies, A. 2003. The native speaker: myth and reality. Clevedon, UK: Multilingual Matters.

Emerson, M. O. \& Smith, Christian. (2000). Divided by faith: Evangelical religion and the problem of race in America. New York, NY: Oxford University Press.

Fishman, J. A. (1989). Language and ethnicity in minority sociolinguistic perspective. Clevedon, UK: Multilingual Matters.

Giles, H., Bourhis, R.\&Taylor, D. M. (1977). Towards a theory of language inethnic intergroup relations. In Howard Giles (Ed.), Language ethnicity and intergrouprelations, 307-348. London, UK: Academic Press.

Harwood, J., Giles, H.\&Bourhis, R. Y. (1994). The genesis of vitality theory:historical patterns and discoursal dimensions. International Journal of Sociology ofLanguage, 108, 167-206.

Hutchinson, J.\&Smith, A. D. (Eds.). (1996). Ethnicity. New York, NY: OxfordUniversity Press.

Isajiw, W. W. (1993). Definition and dimensions of ethnicity: A theoretical framework.In Statistics Canada \& U.S. Bureau of the Census (Eds.), Challenges of measuring an ethnic world: science politics and reality. Proceedings of the Joint Canada-United StatesConference on the Measurement of Ethnicity, 407-427. Washington, D.C.: U.S. GovernmentPrinting Office.

Jones, S. (Ed.). (1997). The archaeology of ethnicity: constructing identities in the past and present. New York, NY: Routledge.

Maher, John. (2005). Metroethnicity, language and the principle of cool. International Journal ofthe Sociology of Language, 11, 83-102.

Maher, J. (2010). Metroethnicities and metrolanguages. In Nikolas Coupland (Ed.), Thehandbook of language and globalization, 575-591. West Sussex, UK: Wiley-Blackwell.

Pennycook, A. (2003). Global englishes, rip slyme and performativity. Journal of Sociolinguistics, 7(4), 513-533.

Pennycook, A. (2004). Performativity and language studies. Critical Inquiry in LanguageStudies, 1(1). $1-26$.

Pennycook, A. (2007a). The rotation gets thick. the constraints get thin: creativity, recontextualization, and difference. Applied Linguistics, 28(4), 579-596.

Pennycook, A. (2007b). Global Englishes and transcultural flows. London, UK: Routledge. 
Pennycook, A. (2007c). Language, localization and the real: Hip-hop and the global spreadof authenticity. Journal of Language, Identity and Education, 6(2), 101-116.

Phinney, J. S., Horenezyk, G.,Liebkind, K.\& Paul Vedder. (2001). Ethnic identity,immigration, and well being: an interactional perspective. Journal of Social Issues 57(3),493-510.

Phinney, J. S., Romero, I., Nava, M.\&Huang, Dan. (2001). The role of language, parents, and peers in ethnic identity among adolescents in immigrant families. Journal of Youthand Adolescence,30(2), 135-153.

Portes, A. \&Rivas, A. (2011). The adaptation of migrant children. Future of Children,21(1), 219-246.

Ramanathan, V.\&Pennycook, A.(2008). Articulating identities: communities,histories, migrations. TESOL in Context, 18(2), 22-40.

Sachdev, I. (1995). Language and identity: ethnolinguistic vitality of aboriginal peoplesin Canada. The London Journal of Canadian Studies, 11, 41-59.

UNDP. (1994). Human Development Report 1994: New Dimensions of Human Security. New York, NY:Oxford University Press.

UNESCO. (2003). Language vitality and endangerment. UNESCO Ad Hoc Expert Group on Endangered Languages. Paris. http://www.unesco.org/culture/ich/doc/src/00120EN.pdf(accessed July 2014).

Zimmermann, K. F. (2007).Migrant Ethnic Identity: Concept and Policy Implications. Forschungsinstitutzur Zukunft der ArbeitInstitute for the Studyof Labor. 